\title{
Cosmos ou caos
}

\section{Agradeço a professora Mariella Augusta Pereira que, com seus conhecimentos filosóficos e literários, apresentou críticas e sugestões possibilitando que este trabalho não se tornasse puramente técnico.}

\section{Resumo}

Neste trabalho, propõe-se uma rápida apreciação da aleatoriedade e do determinismo mediante os conceitos do empirismo e da intuição. Aborda-se sucintamente a teoria do caos, vez que é extremamente complexa. Cumpre ressaltar que tal teoria vem ganhando importância em todos os ramos do conhecimento científico.

\section{Abstract}

This study suggests a quickly appreciation on aleatority and determinism against concepts of empiricism and intuition. The chaos theory is shortly approached due to its complexity. It is important to mention that this theory is currentlly standing out in every branch of scientific knowledge.

Albert Einstein estava errado, ou não, ao afirmar que Deus não joga dados. $\mathrm{O}$ pai da relatividade estava profundamente impregnado de Espinosa, acreditamos, quando afirmou sua determinística frase. Até o acuro da física quântica, o mundo das ciências acreditou no mundo bem amarrado, pronto aos olhos do observador, sistemas passivos, desprezando o logaritmo que vai resultar da entropia, por exemplo. Enfim, para a física clássica havia tal ordem no mundo que estava legitimada como leis, apreendidas e reconhecidas peloempirismo - pretendia-se uma exatidão. Contudo, a física contemporânea ensina a existência inapelável das variações, a negação do determinismo pela liberdade das probabilidades, dos movimentos, vivos, impre- visíveis com os quais nada é realmente exato. Resta-nos, depois do supracitado, aceitar o novo modo de se compreender a física ou justificar Einstein. Na segunda hipótese, poderíamos dizer que, embora os resultados nos pareçam imprevisíveis e não regidos por leis, não significa que não o são, e sim que simplesmente possamos, o que a filosofia jamais descartaria (lembrando a crítica que Kant faz à razão humana) desconhecê-las quer a priori quer a posteriori.

O escopo do artigo que segue é lembrar ao homem que durante muito tempo reivindicou seu papel de criatura semelhante ao criador, acreditando que não tardaria a dominar as leis da natureza, a frase inesquecível de Hamlet a Horácio reconhecendo que ela é a definição que o Drama deu à teoria do caos.

Imaginemos o sucesso alcançado pelo grego Tales de Mileto, quando, ainda no século Vll a.C., fora capaz de prever um eclipse solar - com uma precisão de dois anos (um absurdo, para a época), justamente num momento crucial da batalha entre lídios e medos... Claro que as previsões são mais facilmente aceitas, quando em conformidade com os padrões vigentes. Galileu, com seu gênio desafiador, provocou a ira dos seus contemporâneos ao defender o sistema heliocêntrico, tendo inclusive que se desmentir ante o tribunal da Inquisição, para poder salvar sua vida e já estávamos no século XVll.

Mas nasceria na Inglaterra, em 1642, Isaac Newton que nos deu de presente o "sistema do mundo", com sua obra "Princípios matemáticos de filosofia natural", afirmando que todo movimento poderia ser reduzido a três leis simples.

\footnotetext{
* Mestrando em Economia no IBMEC-RJ. Professor dos cursos de Administração e Ciências Econômicas das Faculdades Integradas "Campos Salles" e da Fundação Armando Álvares Penteado - FAAP.
} 
Quando não sujeitos a ação de forças, os corpos permanecem em repouso ou movimento retilíneo uniforme; se alguma força estiver atuando, a aceleração será proporcional à mesma; e, a toda força há uma reação igual, em sentido contrário. Parece-nos fácil. Bastava-nos apenas determinar as leis que regem o movimento para predizermos os resultados. Lançando mão de recursos matemáticos através de sistemas integráveis, uma vez que o experimento fosse passível de averiguação, restaria comprovado o princípio atuante.

Muitas vezes, os cientistas deparavam com resultados divergentes do esperado, mas esses eram normalmente postos de lado e atribuídos a falhas durante a coleta de dados. Note-se o desprezo completo pelas variações não conhecidas. O mais interessante era a certificação do futuro, ainda que de uma realidade presente aproximada. Laplace formulou de maneira célebre o pensamento determinista. "Uma inteligência que, para um instante dado, conhecesse todas as forças de que está animada a natureza e a situação respectiva dos seres que a compõem, e se, além disso, essa inteligência fosse ampla o suficiente para submeter esses dados à análise, ela abarcaria na mesma fórmula os movimentos dos maiores corpos do Universo e o do mais leve átomo - nada seria incerto para ela, e tanto o futuro como os passados estariam presentes aos seus olhos. O espírito humano oferece, na perfeição que foi capaz de dar a astronomia, um esboço dessa inteligência". Assim, não havia mais lugar para o acaso. Até mesmo num simples "cara ou coroa", se pudéssemos definir a velocidade inicial do lançamento e o período rotacional da moeda, saberíamos de antemão o resultado.

Porém, nem sempre o êxito obtido na formulação das equações era acompanhado por sua resolução. Passoû-se a um processo de autoseleção, concentrando o interesse por problemas solucionáveis. Em nome da Ciência (e do orgutho humano), desprezava-se qualquer fator que ainda não estivesse sob o domínio matemático, acreditando-se que em breve tudo poderia ser solucionado. Vivíamos num mundo idealizado, de sistemas exclusivamente lineares - onde todas as forças atuantes num corpo podem ser estudadas separadamente e seus resultados somados. Há uma piada sobre um fazendeiro riquíssimo que, desejoso de aumentar a produção leiteira do seu gado, contratou uma equipe de excelentes cientistas para desenvolver uma nova técnica. Após um determinado tempo, recebeu o relatório, que começava com a frase - "Imagine uma vaca redonda..."

Estudava-se a força de atração entre dois corpos no espaço, mas não se determinava o resultado da interação de três corpos ao mesmo tempo. Em 1887, o Rei Oscar da Suécia ofereceu um prêmio a quem respondesse satisfatoriamente a questão. "O Sistema Solar é estável?" matemático Poincaré levou o prêmio, não por têla respondido exatamente, mas por ter proporcionado grande avanço em torno dessa questão. E o que se entende por estabilidade? É a tendência que um corpo tem de permanecer em equilíbrio numa determinada situação de repouso ou movimento. Um prego deitado numa superfície horizontal está num estado estável. Se equilibrado sobre sua ponta (algo difícil, mas não propriamente impossível), estará numa situação altamente instável, em que um simples piscar de olhos em outro planeta pode derrubá-lo. Poincaré inventou a topologia, ou seja, a matemática da continuidade - mudanças suaves, sem interrupção. Através de uma mudança contínua, podemos transformar, de maneira reversível, um quadrado num círculo, um círculo num triângulo, um triângulo num paralelogramo, como um ceramista que modela um bocado de argila em suas mãos, sem retirar material.

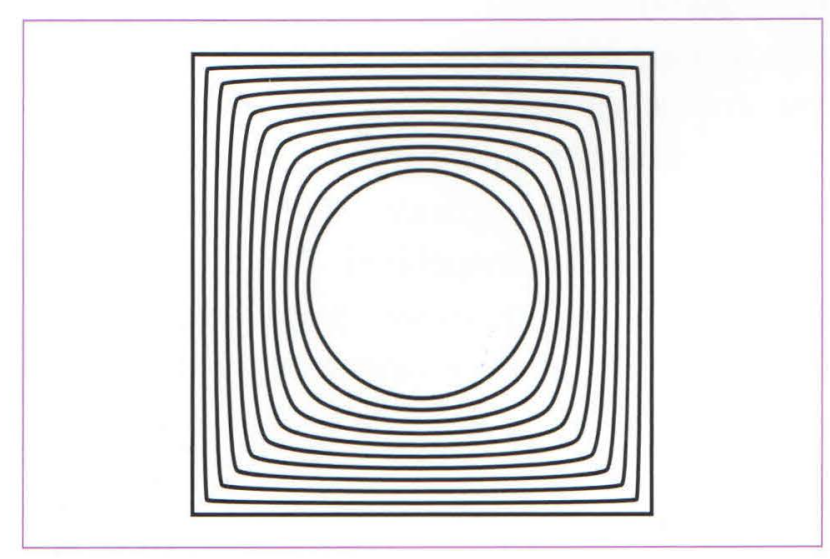


Poincaré imaginou um sistema em movimento periódico descrito pela curva formada por uma seqüência de pontos num espaço de fase, evoluindo até o encontro de mesmas coordenadas de velocidade e posição. Traçando-se um plano perpendicular à trajetória, estuda-se topologicamente a relação entre os pontos que o cortam consecutivamente.

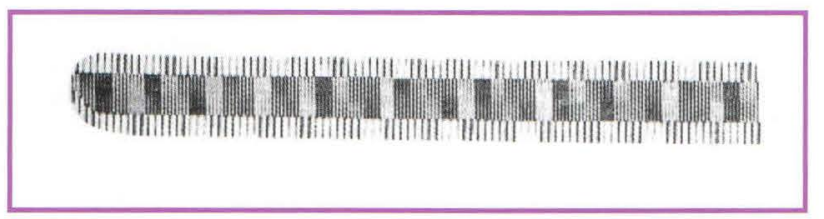

Ao concentrar-se no estudo de três corpos no espaço - Netuno, Plutão e um grão de poeira interestrelar - como se fossem os únicos do Universo, Poincaré observou algo muito complexo, que o deixou aterrorizado. Esse modelo simples gerava uma rede infinitamente apertada, esticada e dobrada de modo que o sistema atravessava a seção de Poincaré numa seqüência aleatória de pontos.

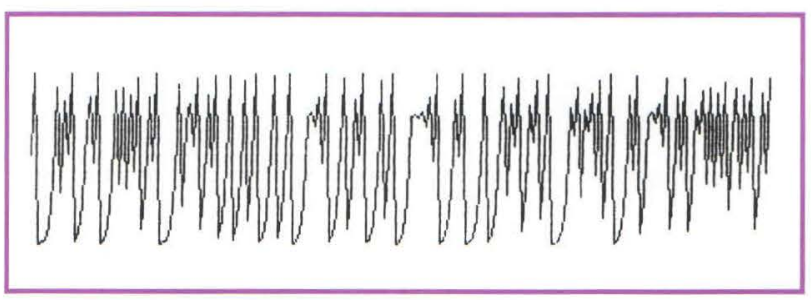

Hoje, sabemos que os sistemas não-lineares são antes regra do que exceção. Mesmo movimentos simples de causas determinísticas podem gerar resultados aparentemente aleatórios, sendo extremamente sensíveis às condições iniciais.

Por exemplo, num jogo de bilhar comum, duas bolas partindo com a mesma velocidade de posições muito semelhantes alcançarão praticamente a mesma posição final, já que o desvio será o mesmo para as duas (o ângulo de refração pelo obstáculo reto é o mesmo de incidência, como num espelho). Já, se tivermos obstáculos fixos redondos na mesa, mesmo que as bolas tenham partido com uma infinitesimal diferença de posição, chegarão a posições completamente diferentes (atingem os obstáculos com ângulos diferentes em relação a normal da circunferência).

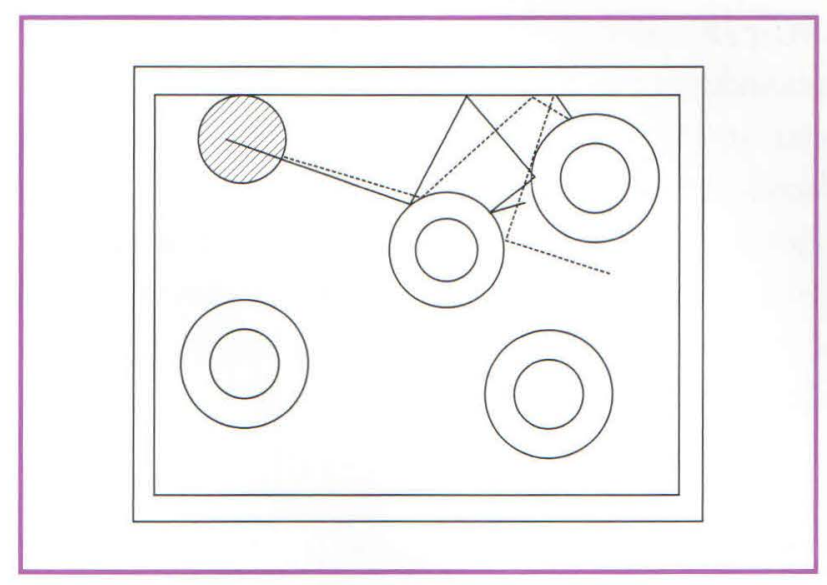

O metereologista Edward Lorenz dava início à febre do caos em 1961, quando tentava fazer previsões a respeito do clima em Massachussets com seu computador. Um dia, em seqüência a um trabalho já iniciado, para economizar tempo - os computadores eram extremamente lentos e barulhentos - Lorenz, evitando a repetição dos cálculos da véspera, digitou os resultados obtidos e saiu para tomar um café. Qual não foi sua surpresa ao voltar, quando encontrou resultados completamente diferentes do esperado. Conferiu os números digitados e não entendia o que tinha acontecido. Só depois se lembrou de ter feito uma aproximação, digitando o número com três casas decimais ao invés de seis. Estudando melhor o ocorrido, desenhou em papel vegetal as duas curvas e sobrepôs as folhas. Notou que inicialmente as curvas ascendentes equivaliam-se, mas com o tempo estavam completamente defasadas e concluiu que, em sistemas físicos não-periódicos, as previsões tornam-se impossíveis - é o chamado Efeito Borboleta, em que o simples bater de asas de uma borboleta no Japão pode afetar o clima no Brasil.

Pouco depois, Smale, um topologista norteamericano, concluía que caos e instabilidade não eram a mesma coisa. Um sistema caótico pode manter suas características diante de pequenas perturbações (ruídos) - é globalmente estável, 
apesar de localmente imprevisível. Utilizando-se da topologia, com sua concentração voltada para o que acontecia com o espaço de fase e não com a trajetória em si, percebeu que a forma do sistema encolhia-se como um balão que perde gás. Traduziu seu pensamento num outro tipo de modelo, conhecido como Ferradura de Smale - algo como esticar um retângulo, transformando-o numa barra horizontal, depois dobrar uma ponta sobre a outra (como uma ferradura), fazendo-o voltar ao seu formato original; repetir o processo inúmeras vezes. Foi o ponto de partida de uma nova intuição sobre o estudo do movimento caótico.

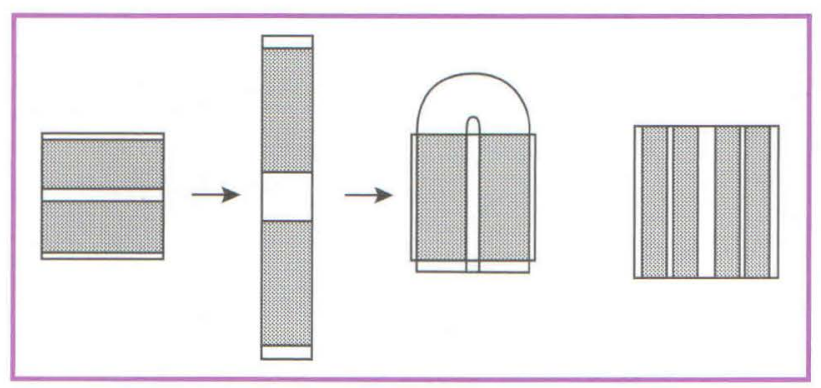

Agora, com uma simples calculadora, vamos brincar um pouquinho com iterações para um número entre 0 e 1 , com várias casas decimais. Por exemplo, apertando-se o botão $\mathrm{x}^{2}$ inúmeras vezes, chegaremos a 0 . Se apertarmos o botão $1 \backslash \mathrm{x}$, teremos uma iteração periódica, de período 2. Vejamos uma equação do tipo $\mathrm{kx}^{2}-1$. Para $\mathrm{k}=1$, teremos um movimento variando de $0 \mathrm{a}-1$. Para $k=2$, os resultados parecem totalmente aleatórios. Tentando outros valores para $\mathrm{K}$, veremos que, às vezes, após inúmeras iterações, os resultados que pareciam aleatórios começam a girar em torno de valores fixos.

Tomemos o exemplo de um sistema dinâmico discreto - um ponto movendo-se por um círculo de uma unidade, em intervalos de tempo representado por números inteiros. Dividimos o círculo em 10 partes - setores de 0 a 9 (setor 0 indo de 0 a $0.9999 \ldots$; setor 1 , de 1 a $1.9999 \ldots$; assim por diante). Fazendo-se um mapeamento do tipo $x$ indo para $10 x$, com o círculo enrolado sobre si mesmo 10 vezes, vamos marcando o itinerário do ponto. Partindo-se, por exemplo, de 0,1465228, dizemos que o número vive no setor 1 . Ao apli- carmos o mapeamento, expande-se para 1,465228 . Uma volta completa simplesmente o leva de volta ao zero e o mesmo faz a unidade, dando como resultado o mesmo ângulo de 0,465228 - setor 4. Iterando-se o mapeamento, observamos o seguinte.

\begin{tabular}{|llll|}
\hline Tempo 0 & 0,1465228 & & setor 1 \\
\hline Tempo 1 & 1,465228 & $=0,465228$ & setor 4 \\
\hline Tempo 2 & 4,65228 & $=0,65228$ & setor 6 \\
\hline Tempo 3 & 6,5228 & $=0,5228$ & setor 5 \\
\hline Tempo 4 & 5,228 & $=0,228$ & setor 2 \\
\hline Tempo 5 & 2,28 & $=0,28$ & setor 2 \\
\hline Tempo 6 & 2,8 & $=0,8$ & setor 8 \\
\hline Tempo 7 & 8 & $=0,0$ & setor 0 \\
\hline
\end{tabular}

Olhando para os setores visitados, notaremos que correspondem aos algarismos decimais do ponto inicial. Assim, se tomarmos dois números iguais até a milésima casa decimal, suas trajetórias serão iguais até a milésima iteração.

Seguindo o mesmo esquema de esticar e enrolar, porém para um espaço tridimensional, teremos um toro, com tirinhas finíssimas sobrepostas, sem que uma toque a outra. Chamamos a esse toro de solenóide. Se tomarmos uma seção transversal do solenóide, teremos um "queijo de Cantor". Mas o que é isso?

Primeiro, vamos ao "Conjunto de Cantor". Desenhamos um segmento de reta de comprimento 1. Dividimos em 3 partes iguais e retiramos a parte central, deixando as extremidades. Repetimos a mesma seqüência para cada uma das partes que restaram e, assim, sucessivamente, até que o intervalo total retirado seja igual a 1 (como o inicial). O comprimento total do Conjunto de Cantor é zero - ele é formado basicamente de buracos.

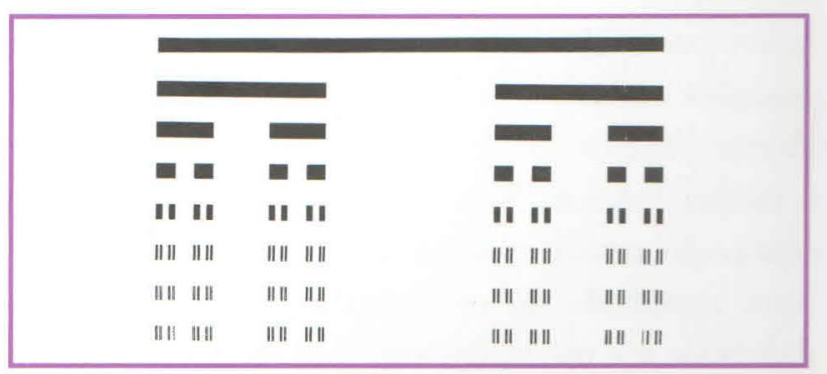


Uma fatia do "queijo de Cantor" seria algo como pegarmos um disco circular, retirarmos dois discos menores de dentro dele e jogarmos o resto fora. Repetindo-se o processo para cada um dos disquinhos, ficamos com discos cada vez menores, até praticamente não sobrar nada, só poeira.

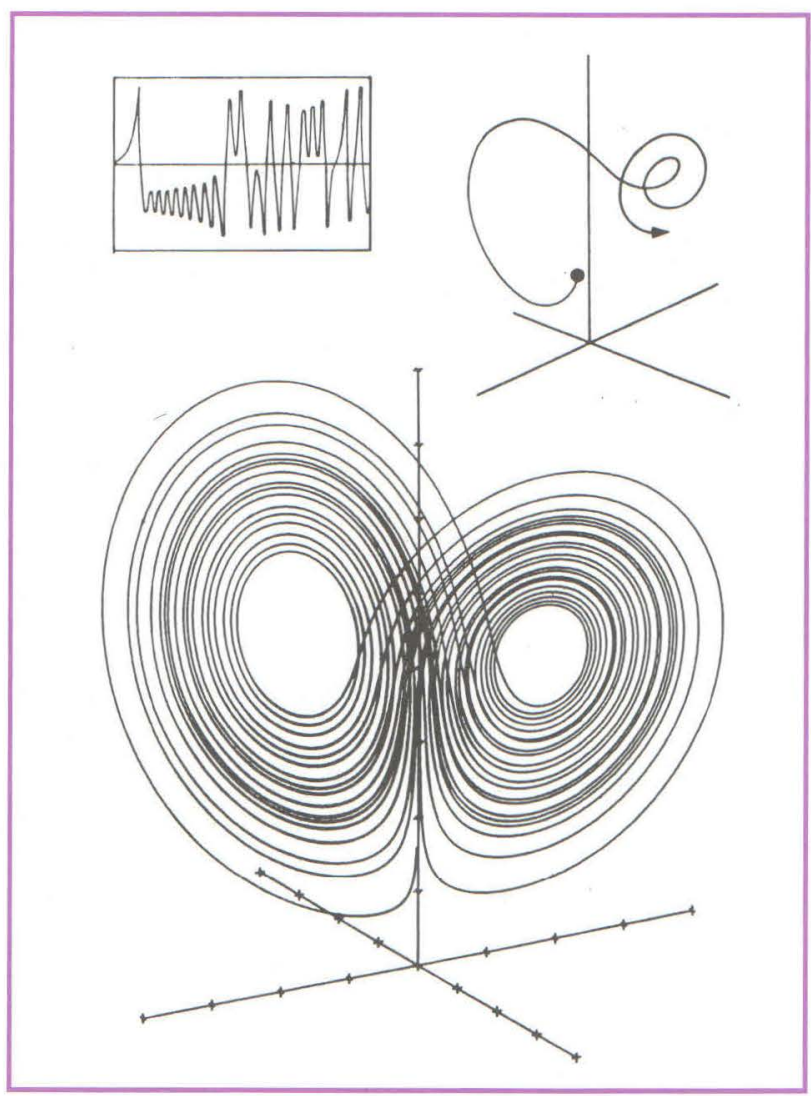

ponto $\mathrm{P}$, partindo próximo a origem das coordenadas, dá uma volta em torno da "orelha" direita do atrator, depois várias voltas pela "orelha" esquerda, depois para a direita... Se o valor inicial for modificado, o aspecto da figura permanece o mesmo, porém o número de voltas sucessivas à esquerda ou à direita torna-se completamente diferente.

Há outra brincadeira interessante a ser feita. Desenhe um triângulo com extensão lateral de uma unidade. Agora, desenhe grudado, no meio de cada lado, um triângulo com laterais equivalentes a $1 / 3$ do tamanho original. Repita a operação para cada um dos três triângulos menores obtidos. Continue repetindo o processo dezena de vezes. $\bigcirc$ que está acontecendo? Temos triân- gulos cada vez menores enquanto a extensão lateral da figura tende ao infinito $(3.4 / 3.4 / 3.4 / 3 \ldots)$, mesmo estando confinada numa área finita (se traçarmos um círculo ao redor do triângulo, veremos que nenhum traço o extrapola). É a chamada curva de Koch - em homenagem ao matemático sueco Helge von Koch, o primeiro a descrevê-la. E qual o resultado dessa multiplicação infinita por $4 / 3$ ? Chegaremos a algo um pouco maior que uma linha (monodimensional), porque ocupa espaço; porém não chega a ser um plano (dimensional) - uma dimensão fracionada, no caso, aproximadamente 1.26 .

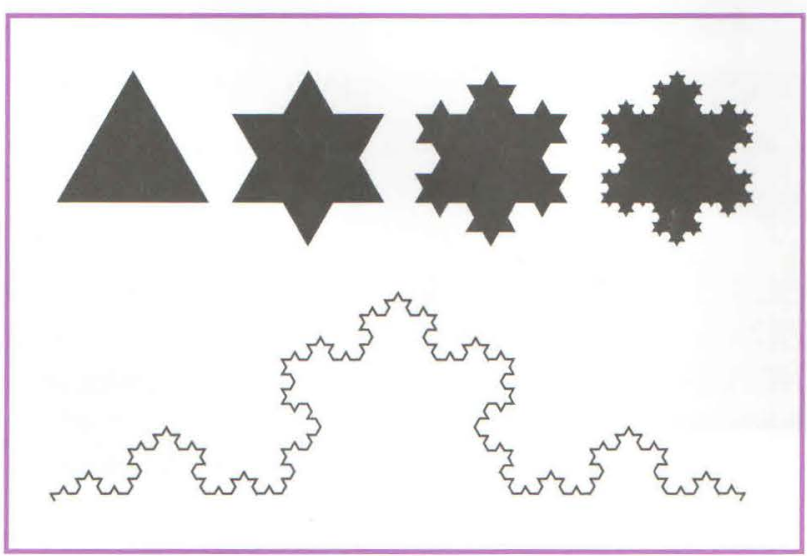

O matemático Mandelbrot foi quem começou a trabalhar em cima da idéia de dimensões diferentes das conhecidas 0, 1, 2 e 3. É necessária uma certa abstração da realidade, para captarmos o significado disso, pois nossa visão é tridimensional. Como usamos planos de fase perpendiculares para determinarmos as três coordenadas de um ponto - três variáveis podemos, por exemplo, trabalhar com quatro variáveis ao mesmo tempo - quatro eixos ortogonais. Vamos tentar imaginar. Dois pontos formam um segmento de linha; um quadrado tem quatro cantos; um cubo tem oito cantos; então, nosso hipercubo teria 16 cantos...

Existem também as dimensões fracionadas, denominadas fractais (como a curva de Koch), que têm como característica principal a autosemelhança; ou seja, se pudéssemos hipoteticamente colocar um pedacinho da figura sob um microscópio, veríamos que a parte corresponde 
ao desenho principal - as escalas são simétricas, com recorrência a um mesmo padrão. Temos inúmeros exemplos dessas estruturas na natureza - asperezas/ rugosidades dos materiais e da própria superfície terrestre; contorno dos litorais; flocos de neve; nuvens; árvores; sistema circulatório; galáxias etc.

No caos determinístico, após as sucessivas duplicações de período, notamos uma correspondência entre as escalas geométricas, o que nos permite aferir sobre possíveis resultados dentro de região específica, em curto prazo - a margem de erro aumenta consideravelmente com o tempo.

Atualmente, os mais inflexíveis pensadores respeitam a física clássica pela sua importância em abrir caminhos para o conhecimento, mas repensam seriamente suas visões deterministas, pois sabem que as condições perfeitamente mensuráveis, que objetos completamente passivos, e observações inócuas simplesmente não existem. Todas as ciências já se valem da tentativa de compreender o caos, ou antes, admiti-lo, inclusive as humanas e as biológicas. Fazem-no por reconhecerem sistemas complexos, englobando inúmeras variáveis. Citemos, como exemplo bastante esclarecedor, a Economia. Como não poderia deixar de ser, fazem-no, porque até Marlamé, na obscuridade da poesia, trouxe a lume a verdade diante da qual devemos nos curvar: "Um lance de dados jamais abolirá o acaso".

\section{REFERÊNCIAS BIBLIOGRÁFICAS}

GLEICK, James. Caos: a criação de uma nova ciência. Rio de Janeiro: Campus, 1987.

GLEISER, Ilan. Caos e Complexidade. Rio de Janeiro: Campus, 2002.

NÓBREGA, Clemente. Em busca da Empresa Quântica: analogias entre o mundo da ciência e o dos negócios. Rio de Janeiro: Ediouro, 1996.

RUELLE, David. Acaso e Caos. São Paulo: Editora da Universidade Estadual Paulista, 1993.

SAGAN, Carl. O mundo assombrado pelos demônios: a ciência vista como uma vela no escuro. São Paulo: Companhia das Letras, 1996.

SCHWENK, Theodor. Sensitive Chaos. Nova York: Schocken Books, 1976.

STEWART, Ian. Os números da natureza: a realidade irreal da imaginação matemática. Rio de Janeiro: Rocco, 1996. Será que deus joga dados? - a nova matemática do Caos. Rio de Janeiro: Jorge Zahar, 1991. 